\title{
Preparation and Characterization of Self-Assembled Manganese Dioxide Thin Films
}

\author{
Suh Cem Pang, Suk Fun Chin, and Chian Ye Ling \\ Department of Chemistry, Faculty of Resource Science and Technology, Universiti Malaysia Sarawak, 94300 Kota Samarahan, \\ Sarawak, Malaysia \\ Correspondence should be addressed to Suh Cem Pang, suhcem@gmail.com
}

Received 5 May 2011; Accepted 20 June 2011

Academic Editor: Mallikarjuna Nadagouda

Copyright ( $\odot 2011$ Suh Cem Pang et al. This is an open access article distributed under the Creative Commons Attribution License, which permits unrestricted use, distribution, and reproduction in any medium, provided the original work is properly cited.

Thin films of manganese dioxide $\left(\mathrm{MnO}_{2}\right)$ were prepared by self-assembly of $\mathrm{MnO}_{2}$ nanoparticles directly unto nickel-coated poly(ethylene terephthalate) flexible films using the newly developed horizontal submersion process. The thickness of deposited thin films was controllable by the deposition duration. This horizontal submersion deposition process for thin-film deposition is relatively easy, simple, and cost effective. Effects of deposition duration and calcination temperatures on the microstructure and electrochemical properties of self-assembled $\mathrm{MnO}_{2}$ thin films were investigated. Optimized $\mathrm{MnO}_{2}$ thin films exhibited high charge capacity, good cycling reversibility, and stability in a mild aqueous electrolyte and are thus promising electrode materials for the fabrication of thin-film electrochemical capacitors.

\section{Introduction}

Manganese dioxide- $\left(\mathrm{MnO}_{2}-\right)$ based thin film electrochemical capacitors have received numerous attentions since Pang et al. reported a specific capacitance value of $720 \mathrm{~F} / \mathrm{g}$ for ultra-thin $\mathrm{MnO}_{2}$ films in a mild aqueous electrolyte $[1,2]$. $\mathrm{MnO}_{2}$ thin films appear to be a promising electrode material in batteries and electrochemical capacitors due to the low cost of raw materials, low toxicity and environmentally benign, and their excellent electrochemical properties [3, 4]. Many routes for the preparation of $\mathrm{MnO}_{2}$ thin films have currently been developed, which include the sol-gel process, electrodeposition [5-7], and atomic layer deposition [8]. More recently, the self-assembly technique has emerged as one of the most promising methods for thin film fabrication [9]. Self-assembly is the spontaneous adsorption process by which molecules or nanoparticles are arranged into organized aggregates, networks, or patterns onto a supporting substrate. It is characterized as being relatively simple, inexpensive, and requires low energy consumption.

In this study, we have attempted to prepare selfassembled manganese dioxide $\left(\mathrm{MnO}_{2}\right)$ thin films directly on nickel-coated poly(ethylene terephthalate) (Ni/PET) flexible supporting substrate using the newly developed horizontal submersion process under ambient conditions. This thin film deposition process is very cost effective, rapid, and conformal in the preparation of nanostructured thin films which are suitable for the fabrication of thin film electrochemical capacitors. Most notably, the thickness of deposited film is controllable simply by the duration of submersion or by repeating the deposition process a desired number of times. Physical and electrochemical characterization of manganese dioxide nanoparticles and self-assembled thin films was conducted using various established characterization techniques. The effect of deposition conditions on the microstructure and electrochemical properties of selfassembled manganese dioxide thin films were investigated.

\section{Materials and Methods}

2.1. Preparation of $\mathrm{MnO}_{2}$ Colloidal Suspension (sol). Stable $\mathrm{MnO}_{2}$ colloidal suspension ( $\mathrm{sol}$ ) was prepared based on a method reported in literature [10]. Typically, $\mathrm{MnO}_{2}$ sol was prepared by mixing $4 \mathrm{~mL}$ of $\mathrm{KMnO}_{4}\left(1.0 \times 10^{-1} \mathrm{~mol} / \mathrm{L}\right)$ and $8 \mathrm{~mL}$ of $\mathrm{Na}_{2} \mathrm{~S}_{2} \mathrm{O}_{3}\left(1.88 \times 10^{-2} \mathrm{~mol} / \mathrm{L}\right)$ in $38 \mathrm{~mL}$ ultrapure water $\left(18.2 \mathrm{M} \Omega\right.$ ). The resulting dark-brown $\mathrm{MnO}_{2}$ sol was 


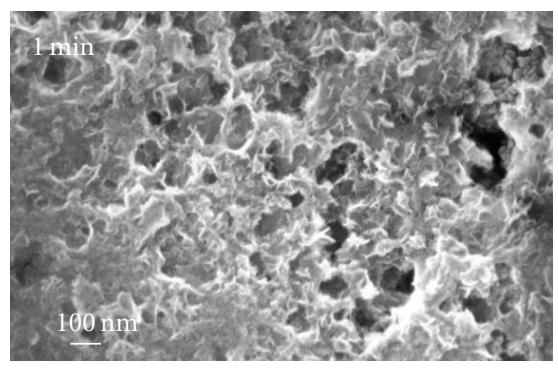

(a)

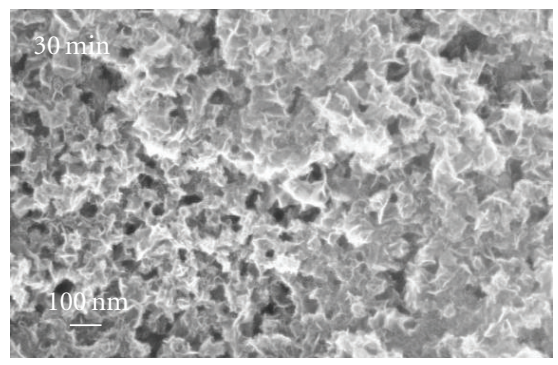

(c)

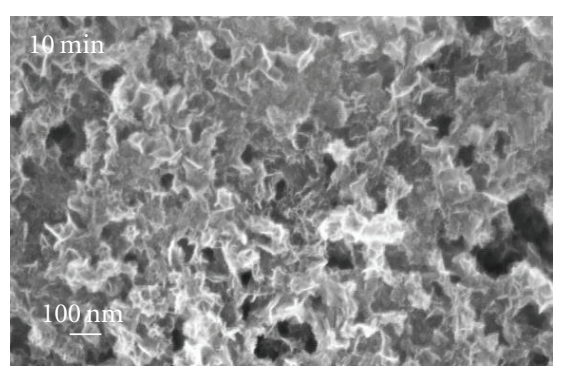

(b)

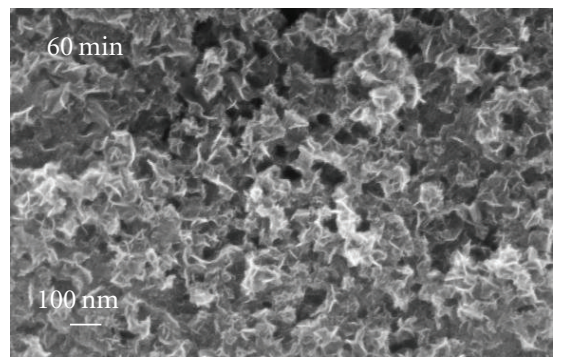

(d)

FIGURE 1: FESEM micrographs of self-assembled $\mathrm{MnO}_{2}$ thin films deposited on Ni/PET substrates at various submersion durations (a) $1 \mathrm{~min}$, (b) $10 \mathrm{~min}$, (c) $30 \mathrm{~min}$, and (d) $60 \mathrm{~min}$.

being dispersed by sonication in order to enhance dispersion to form a stable colloidal suspension.

2.2. Preparation of Self-Assembled $\mathrm{MnO}_{2}$ Thin Films. Selfassembled $\mathrm{MnO}_{2}$ thin films were prepared on nickel-coated poly(ethylene terephthalate) supporting substrate (Ni/PET) using the newly developed horizontal submersion process. Precleaned Ni/PET substrate with a surface area of $\sim 3 \mathrm{~cm}^{2}$ was positioned horizontally onto glass slides using adhesive tape and placed into petri dishes. The $\mathrm{MnO}_{2}$ sol was sonicated for 5 minutes to ensure well-dispersed nanoparticles before being poured into the petri dishes. A measured volume of $\mathrm{MnO}_{2}$ sol was then poured into each petri dish to completely submerse the substrate. Self-assembled $\mathrm{MnO}_{2}$ thin films were formed spontaneously on the substrates upon submersion within the sol for the desired duration. The relative film thickness was controlled by the duration of submersion in the sol. All deposited films were air dried at ambient temperature and subsequently calcined in a tube furnace at various temperatures in air for an hour.

\subsection{Characterizations of $\mathrm{MnO}_{2}$ Nanoparticles and Thin Films.} The surface morphology of $\mathrm{MnO}_{2}$ nanoparticles and selfassembled thin films were characterized using a scanning electron microscope (SEM) (JEOL Model JSM 6390LA) and a field emission scanning electron microscope (FESEM) (LEO Model 1535), respectively, at various magnifications. All samples were coated with platinum using a sputtering device JFC-1100 E to reduce the inherent charging effect. A transmission electron microscope (TEM) (Model JEM1230) was used to study the surface morphology of $\mathrm{MnO}_{2}$ nanoparticles. The elemental composition of the $\mathrm{MnO}_{2}$ nanoparticles was analyzed by FESEM-associated energy dispersive X-ray microanalysis (EDX) operated with a beam energy of $10 \mathrm{kV}$.

The electrochemical characterization of self-assembled $\mathrm{MnO}_{2}$ thin films was conducted using an advanced electrochemical analyzer (PARSTAT 2263). Sample evaluation by cyclic voltammetry (CV) was conducted using a standard three-electrode cell configuration. The reference electrode used was a saturated calomel electrode (SCE) fitted with a Vycor bridge, and the counter electrode was a platinum foil $\left(\sim 2 \mathrm{~cm}^{2}\right)$. A geometric electrode area of $0.1257 \mathrm{~cm}^{2}$ of thin-film sample was being exposed to the electrolyte during all cyclic voltammetric experiments. Cyclic voltammograms were obtained by scanning over the potential range of $0.0 \mathrm{~V}-$ $0.9 \mathrm{~V}$ (versus SCE), with a scan rate of $50 \mathrm{mV} / \mathrm{s}$ in $1.0 \mathrm{M}$ $\mathrm{Na}_{2} \mathrm{SO}_{4}$ aqueous solution as electrolyte.

The mass loading of various self-assembled $\mathrm{MnO}_{2}$ films was determined quantitatively by atomic absorption spectroscopy (AAS) after dissolving a known area of films in the $\mathrm{H}_{2} \mathrm{O}_{2} / \mathrm{HNO}_{3}$ solution mixture. Based on the measured $\mathrm{Mn}$ concentration, the mass loading of $\mathrm{MnO}_{2}$ per unit of electrode area was calculated using the formula weight of stoichiometric $\mathrm{MnO}_{2}$ of $86.94 \mathrm{~g} / \mathrm{mol}$.

\section{Results and Discussion}

3.1. Effect of Submersion Duration. Figure 1 shows SEM micrographs of self-assembled $\mathrm{MnO}_{2}$ thin films deposited on Ni/PET substrate by the horizontal submersion process at various submersion durations under ambient conditions. These films showed good adhesion to the substrate even without the addition of any binder. Self-assembled films deposited at shorter submersion duration were observed to be rather porous with loosely packed nanoclusters, 


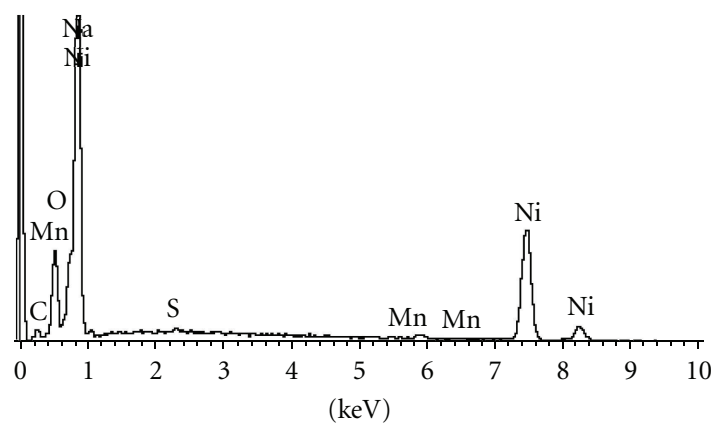

Full scale 3109 cts cursor: 0.000

(a)

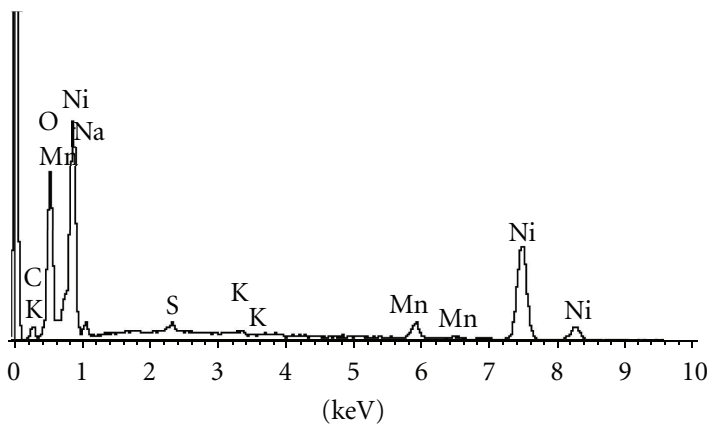

Full scale 3109 cts cursor: 0.000

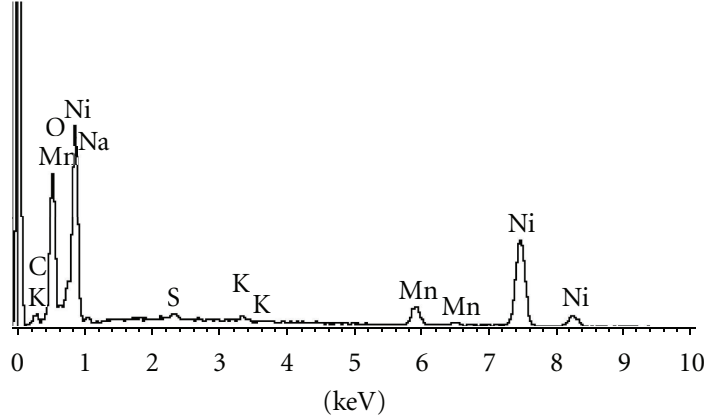

Full scale 3109 cts cursor: 0.000

(b)

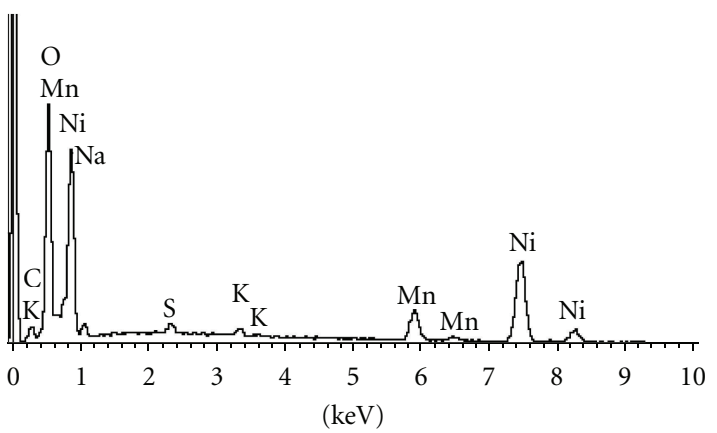

Full scale 3109 cts cursor: 0.000

(c)

(d)

FIgURE 2: EDX spectra of self-assembled $\mathrm{MnO}_{2}$ thin films on Ni-coated PET films at submersion duration of (a) 1 min, (b) 10 min, (c) $30 \mathrm{~min}$, and (d) $60 \mathrm{~min}$.

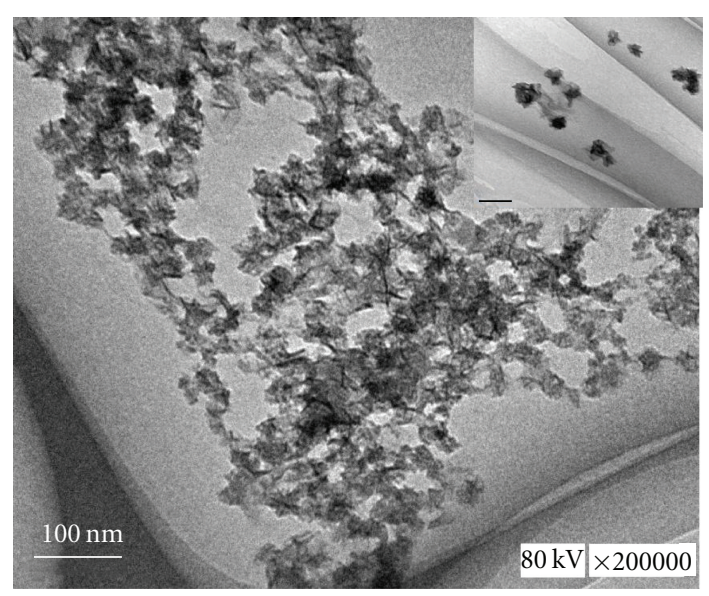

Figure 3: TEM micrographs of $\mathrm{MnO}_{2}$ self-assembled thin films as deposited on $\mathrm{Ni} / \mathrm{PET}$ supporting substrate. Inset showed welldispersed nanoclusters and individual nanoparticles.

whereas films deposited at longer submersion duration were denser with closely packed nanoclusters. Figure 2 shows the EDX spectra of self-assembled manganese oxide thin films on Ni/PET substrates. The presence of manganese and oxygen atoms in the elemental composition of deposited thin films confirmed the deposition of $\mathrm{MnO}_{2}$ thin films. Besides, the weight percentages of $\mathrm{Mn}$ and $\mathrm{O}$ elements within the deposited films were observed to increase with increased submersion durations, indicating the deposition of thicker films. The weight percentage of Mn was observed to have increased from $1.42 \%$ to $8.74 \%$, whereas that of $\mathrm{O}$ was increased from $10.85 \%$ to $25.56 \%$ as the submersion duration was increased from 1 minute to 60 minutes.

Figure 3 shows TEM micrographs of self-assembled $\mathrm{MnO}_{2}$ thin film as deposited on Ni/PET supporting substrate. Well-dispersed manganese dioxide nanoclusters and well-defined individual nanoparticles could be clearly discernable (insets of Figure 3 ). The mean average nanoparticle size was about 20-25 nm in diameter. Aggregated and dense nanofibrous structures were observed to radiate outward from the centre of each nanoparticle.

3.2. Effect of Calcination. The effect of calcination on the surface morphology of self-assembled $\mathrm{MnO}_{2}$ thin films on Ni/PET supporting substrates was studied by FESEM and shown in Figure 4. The heat treatment was observed to have substantial effect on the surface morphology of $\mathrm{MnO}_{2}$ thin films, with calcined films showing comparatively smoother surface morphology with densely packed nanoparticles. Apart from film densification, the calcination process could have effectively removed all physisorbed and chemisorbed water from $\mathrm{MnO}_{2}$ thin films, as evidenced by the porous microstructure and occurrence of cracks due to the shrinkage of films. Such porous microstructures could serve to enhance ionic transport and redox reactions which underlie the 


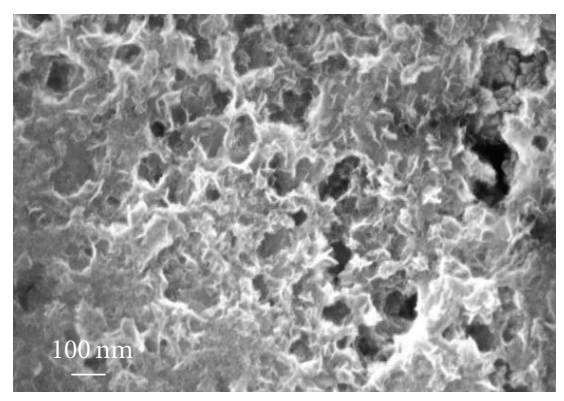

(a)

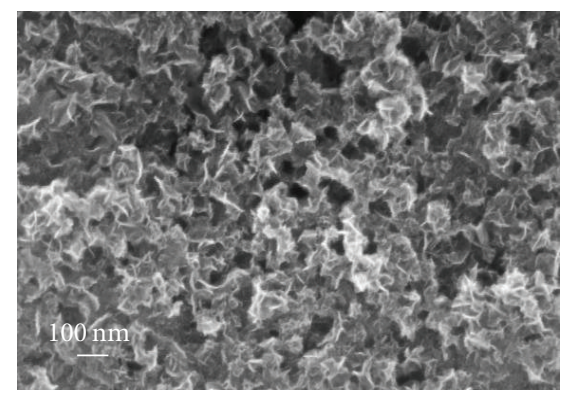

(c)

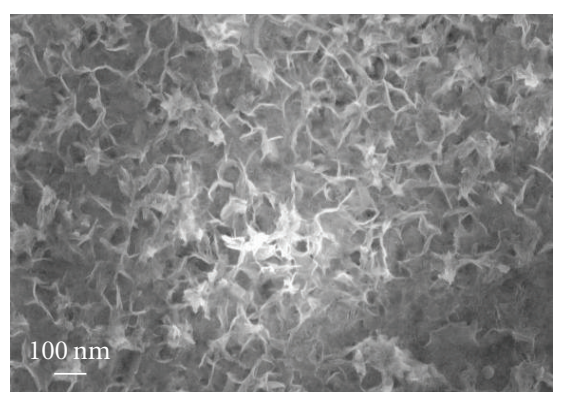

(b)

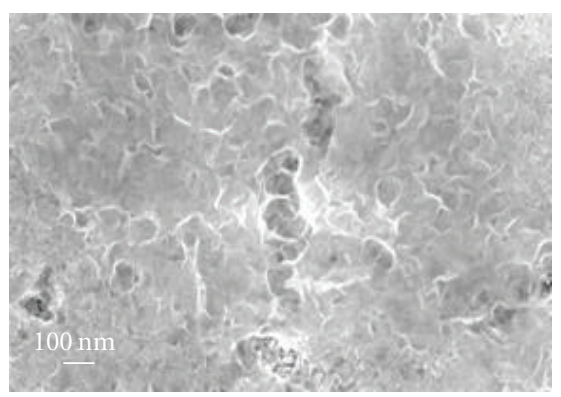

(d)

FIGURE 4: FESEM micrographs of $\mathrm{MnO}_{2}$ thin films on Ni-coated PET films at deposition duration of (a) 1 min, before, (b) 1 min, after, and (c) $60 \mathrm{~min}$, before, (d) $60 \mathrm{~min}$, after calcination at $200^{\circ} \mathrm{C}$ in air for 1 hour.

charge storage mechanism [11]. The electrolyte ions could penetrate into the porous microstructure of manganese dioxide thin-film electrode during electrochemical reactions.

\subsection{Electrochemical Characterization of Self-Assembled $\mathrm{MnO}_{2}$ Thin Films}

3.3.1. Effect of Calcination. The effect of heat treatment on the capacitive behavior of self-assembled $\mathrm{MnO}_{2}$ thin films on $\mathrm{Ni} / \mathrm{PET}$ films was investigated by heating them in air at various temperatures for 1 hour. The calcination temperature did not exceed $200^{\circ} \mathrm{C}$ since the melting point of pure PET was $241^{\circ} \mathrm{C}$ [12]. Calcination temperature was observed to have a positive effect on the charge capacity of $\mathrm{MnO}_{2}$ thin films as shown by the increase in areas of cyclic voltammograms for films calcined at higher temperatures (Figure 5). The charge capacities of $\mathrm{MnO}_{2}$ thin films were observed to increase moderately with increasing calcination temperatures up to $200^{\circ} \mathrm{C}$. A maximum charge capacity of $34 \mathrm{mF} / \mathrm{cm}^{2}$ was achieved for films calcined at $200^{\circ} \mathrm{C}$. Previous studies reported that annealing temperature could affect the crystal structure of the electrochemically deposited manganese oxide [13]. Chemically bound water within the $\mathrm{MnO}_{2}$ films was thought to have played a major role in the observed variation of charge capacity. As chemically bound water is essential for the transportation of active ionic species, the pseudocapacitance of oxide material is dependent upon its water content [14]. Water content in manganese oxides is known to affect the electrochemical reactivity and thermodynamic stability of various manganese dioxide phases as it causes variation of crystal lattice and

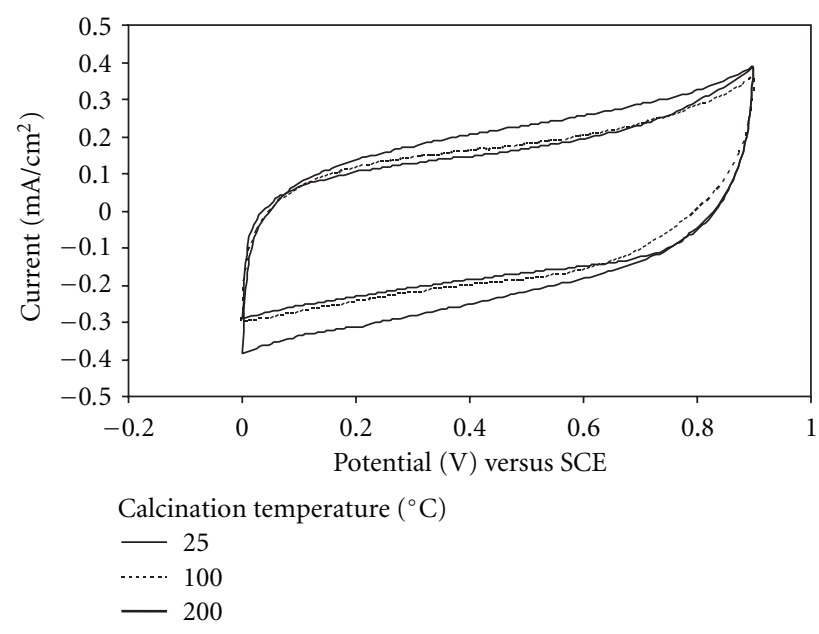

Figure 5: Cyclic voltammograms of self-assembled $\mathrm{MnO}_{2}$ thin films calcined at various temperatures.

consequently of electrical conductivity and electrode potential [15]. Although the presence of structural water promotes proton diffusivity in manganese oxide, its resistivity increases with increasing water content. As such, heat treatment of $\mathrm{MnO}_{2}$ films at $200^{\circ} \mathrm{C}$ in air for 1 hour could have resulted in lowering their structural water content within the oxide lattice and consequently led to increase in the electronic conductivity and hence the observed higher charge capacity.

3.3.2. Effect of Film Thickness. Figure 6 shows the cyclic voltammograms of $\mathrm{MnO}_{2}$ films coated on Ni/PET substrates 


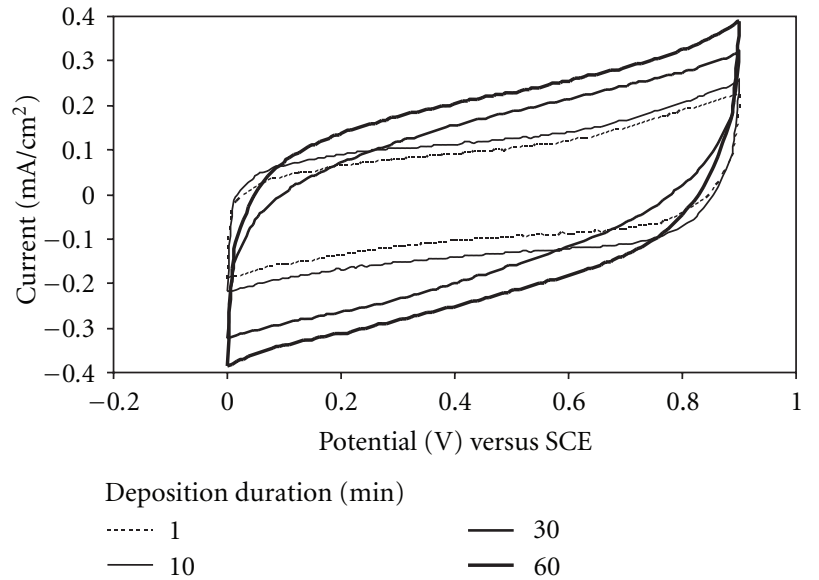

FIgURE 6: Cyclic voltammograms of self-assembled manganese dioxides thin films deposited at different submersion durations.

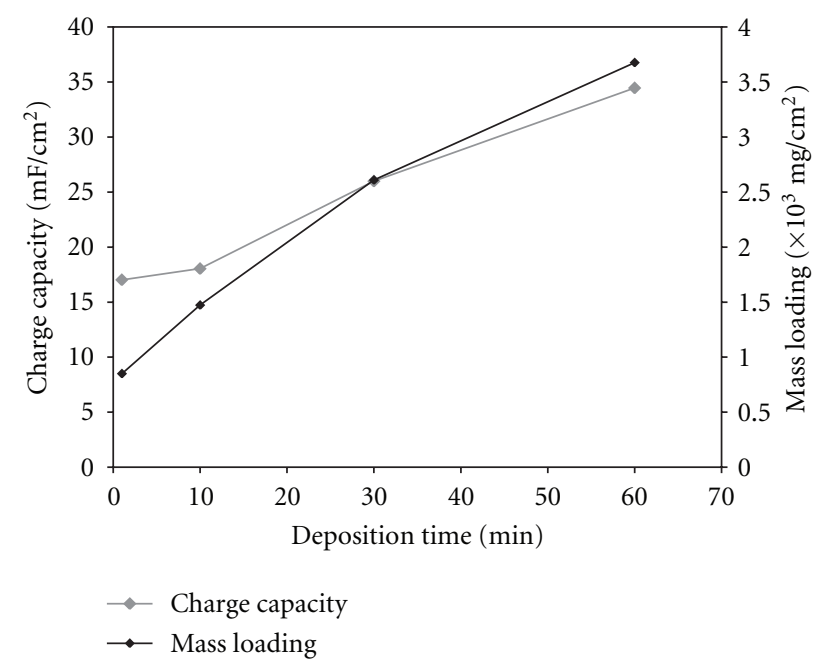

Figure 7: Charge capacity and mass loading of $\mathrm{MnO}_{2}$ thin films deposited at various submersion durations.

at different submersion duration. The relative film thickness was controlled by the submersion duration which was being varied between 1 minute and 60 minutes. All cyclic voltammograms obtained were almost rectangular in shape with symmetrical anodic and cathodic halves. Such rectangular cyclic voltammograms indicated that self-assembled $\mathrm{MnO}_{2}$ films exhibited almost ideal capacitive behaviors. It is clear from Figure 6 that there were no redox peaks observed within the potential range between 0 and $0.9 \mathrm{~V}$ (versus SCE) which could be attributed to the phase stability of electrode materials and the high reversibility of pseudocapacitive electrochemical reactions.

Figure 7 shows the average mass loading and charge capacities of self-assembled $\mathrm{MnO}_{2}$ thin films deposited on $\mathrm{Ni} / \mathrm{PET}$ substrates at various submersion durations. The mass loading of self-assembled $\mathrm{MnO}_{2}$ films deposited on the supporting substrate was used as an indication of their relative film thickness. The mass loadings of $\mathrm{MnO}_{2}$ films deposited on Ni/PET substrates were determined using AAS

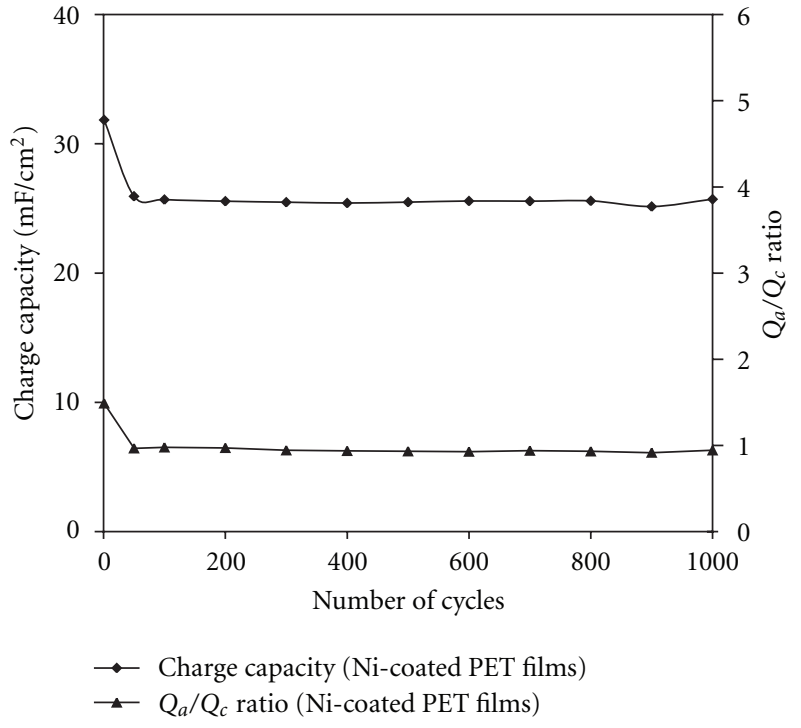

FIGURE 8: Charge capacity and cycling reversibility of self-assembled $\mathrm{MnO}_{2}$ thin films as a function of cycle numbers.

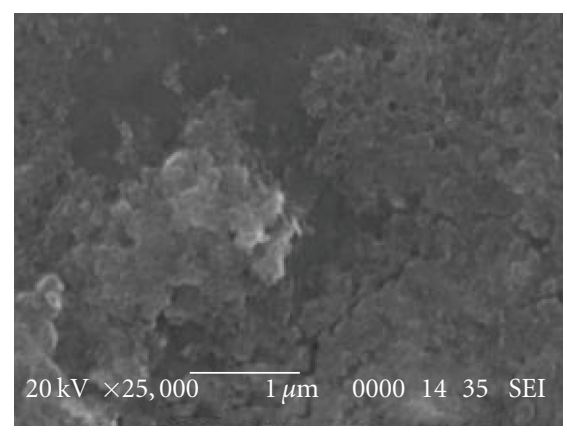

(a)

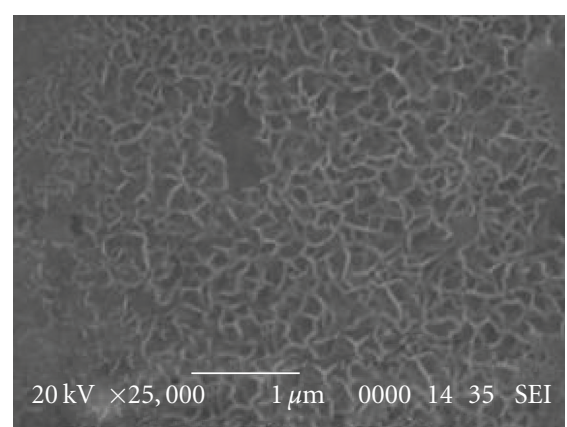

(b)

FIGURE 9: Effect of voltammetric cycling on the microstructure of $\mathrm{MnO}_{2}$ films (a) before cycling; (b) after cycling.

by dissolving these films in $\mathrm{HNO}_{3} / \mathrm{H}_{2} \mathrm{O}_{2}$ mixture. Generally, the mass loading of $\mathrm{MnO}_{2}$ was observed to increase in submersion durations. A maximum mass loading of $3.68 \times$ $10^{-3} \mathrm{mg} / \mathrm{cm}^{2}$ of $\mathrm{MnO}_{2}$ was deposited on Ni/PET substrates at the submersion duration of 60 minutes. Both mass loading and charge capacity of self-assembled $\mathrm{MnO}_{2}$ thin films were observed to increase in tandem with submersion durations. Such increase in charge capacity was associated 
with the higher mass loading of manganese dioxide for thicker films, as also evidenced by the higher weight $\%$ of $\mathrm{Mn}$ as determined by both the EDX and AAS analyses for films deposited at longer submersion durations (Figure 2). The voltammetric charge of the electrochemically oxidized $\mathrm{MnO}_{2}$ films was observed to increase with increasing film thickness, which corresponded to increase in their charge capacity. It was observed that self-assembled $\mathrm{MnO}_{2}$ films possessed highly porous microstructure with high specific surface area and hence favored the proton/cation diffusion and adsorption/desorption during the redox transitions.

3.3.3. Effect of Long-Term Cycling. The effect of long-term cycling of self-assembled $\mathrm{MnO}_{2}$ thin films deposited on $\mathrm{Ni} / \mathrm{PET}$ substrates in $1.0 \mathrm{M} \mathrm{Na}_{2} \mathrm{SO}_{4}$ aqueous solution is shown in Figure 8 . The charge capacity was observed to decline rather rapidly for the initial 100 cycles but only decreased gradually thereafter upon long-term cycling. The overall net loss in charge capacity of $\mathrm{MnO}_{2}$ thin films was observed to be about $19 \%$ of their initial charge capacity upon cycling for 1,000 cycles. Such decline in charge capacity could be attributed to delamination and partial dissolution of manganese dioxide films into the electrolytes during cycling rather than any structural or chemical degradation. Dissolution of $\mathrm{MnO}_{2}$ during discharge in neutral electrolyte occurred by both the disproportionation reaction and solidphase diffusion [1]. However, it is speculated that other factors may also be involved, such as changes in the electronic conductivity of the film during cycling associated with changes in oxidation states or structural water content [2]. The decrease in capacity after cycling can also be attributed to increased electrode resistance with increasing cycle number [16]. The charge capacity was observed to decline rather rapidly for the initial 100 cycles but only decreased gradually thereafter upon long-term cycling. The overall net loss in charge capacity of self-assembled $\mathrm{MnO}_{2}$ thin films was observed to be about $19 \%$ of their initial charge capacity upon cycling for 1,000 cycles.

Figure 9 shows the SEM micrographs of self-assembled $\mathrm{MnO}_{2}$ thin films deposited on Ni/PET films before and after cycling for 1000 cycles. The surface morphology of $\mathrm{MnO}_{2}$ film after cycling was more porous and fibrous in nature. Similar observations had been reported by Nagarajan et al. [17]. The higher porosity could be resulted from partial dissolution and redeposition of manganese oxide during cycling. Since the charge/discharge process in $\mathrm{MnO}_{2}$ involves a redox reaction between the III and IV oxidation states of $\mathrm{Mn}$, the reactivity (or utilization) of the oxide can be enhanced with increased accessibility of electrolyte ions within materials $[16,17]$. In addition, some of the $\mathrm{MnO}_{2}$ inevitably dissolved into the $1.0 \mathrm{M} \mathrm{Na}_{2} \mathrm{SO}_{4}$ electrolyte and then redeposited onto the substrate. The redeposited oxide layer was highly porous and showed a distinctive petal-like surface morphology. This could be attributed to the anodized film caused by back and forth sweeps of the applied cycling potential.

\section{Conclusion}

Self-assembled manganese dioxide thin films have been successfully deposited unto Ni/PET films using the newly developed horizontal submersion process under ambient conditions. These films were shown by cyclic voltammetry to exhibit excellent capacitance behavior, high cycling reversibility, and stability within the potential range of 0.0 to $0.9 \mathrm{~V}$ versus SCE in mild $\mathrm{NaSO}_{4}$ aqueous electrolyte. Thin film with desired thickness, good uniformity and tailored microstructure, and enhanced electrochemical properties could be prepared through optimizing deposition conditions such as submersion duration and calcination temperature.

\section{Acknowledgment}

This work was supported in part by the Ministry of Higher Education Malaysia (MOHE) Fundamental Research Grant Scheme: FRGS/01(18)/747/2010(33).

\section{References}

[1] S. C. Pang, M. A. Anderson, and T. W. Chapman, "Novel electrode materials for thin-film ultracapacitors: comparison of electrochemical properties of sol-gel-derived and electrodeposited manganese dioxide," Journal of the Electrochemical Society, vol. 147, no. 2, pp. 444-450, 2000.

[2] S. F. Chin, S. C. Pang, and M. A. Anderson, "Material and electrochemical characterization of tetrapropylammonium manganese oxide thin films as novel electrode materials for electrochemical capacitors," Journal of the Electrochemical Society, vol. 149, no. 4, pp. A379-A384, 2002.

[3] S. F. Chin and S. C. Pang, "Tetrapropylammonium-manganese oxide/polypyrrole hybrid nanocomposite thin films as novel electrode materials for supercapacitors," Materials Chemistry and Physics, vol. 124, no. 1, pp. 29-32, 2010.

[4] S. F. Chin, S. C. Pang, and M. A. Anderson, "Self-assembled manganese dioxide nanowires as electrode materials for electrochemical capacitors," Materials Letters, vol. 64, no. 24, pp. 2670-2672, 2010.

[5] S. C. Pang and M. A. Anderson, "Novel electrode materials for electrochemical capacitors: part II. Material characterization of sol-gel-derived and electrodeposited manganese dioxide thin films," Journal of Materials Research, vol. 15, no. 10, pp. 2096-2106, 2000.

[6] C. C. Hu and T. W. Tsou, "Capacitive and textural characteristics of hydrous manganese oxide prepared by anodic deposition," Electrochimica Acta, vol. 47, no. 21, pp. 35233532, 2002.

[7] B. Babakhani and D. G. Ivey, "Anodic deposition of manganese oxide electrodes with rod-like structures for application as electrochemical capacitors," Journal of Power Sources, vol. 195, no. 7, pp. 2110-2117, 2010.

[8] O. Nilsen, H. Fjellvåg, and A. Kjekshus, "Growth of manganese oxide thin films by atomic layer deposition," Thin Solid Films, vol. 444, no. 1-2, pp. 44-51, 2003.

[9] X. Zhang, W. Yang, and D. G. Evans, "Layer-by-layer selfassembly of manganese oxide nanosheets/polyethylenimine multilayer films as electrodes for supercapacitors," Journal of Power Sources, vol. 184, no. 10, pp. 695-700, 2008.

[10] J. F. Perez-Benito, C. Arias, and E. Amat, "A kinetic study of the reduction of colloidal manganese dioxide by oxalic acid," 
Journal of Colloid and Interface Science, vol. 177, no. 2, pp. 288297, 1996.

[11] S. C. Pang, W. H. Khoh, and S. F. Chin, "Nanoparticulate magnetite thin films as electrode materials for the fabrication of electrochemical capacitors," Journal of Materials Science, vol. 45, no. 20, pp. 5598-5604, 2010.

[12] Z. Fang, R. L. Smith, H. Inomata, and K. Arai, "Phase behavior and reaction of polyethylene terephthalate-water systems at pressures up to $173 \mathrm{MPa}$ and temperatures up to $490^{\circ} \mathrm{C}$," Journal of Supercritical Fluids, vol. 15, no. 3, pp. 229-243, 1999.

[13] M. S. Wu and R. H. Lee, "Nanostructured manganese oxide electrodes for lithium-ion storage in aqueous lithium sulfate electrolyte," Journal of Power Sources, vol. 176, no. 1, pp. 363$368,2008$.

[14] S. J. Bao, B. L. He, Y. Y. Liang, W. J. Zhou, and H. L. $\mathrm{Li}$, "Synthesis and electrochemical characterization of amorphous $\mathrm{MnO}_{2}$ for electrochemical capacitor," Materials Science and Engineering A, vol. 397, no. 1-2, pp. 305-309, 2005.

[15] A. Era, Z. Takehara, and S. Yoshizawa, "Discharge mechanism of the manganese dioxide electrode," Electrochimica Acta, vol. 12, no. 9, pp. 1199-1212, 1967.

[16] B. Babakhani and D. G. Ivey, "Anodic deposition of manganese oxide electrodes with rod-like structures for application as electrochemical capacitors," Journal of Power Sources, vol. 195, no. 7, pp. 2110-2117, 2010.

[17] N. Nagarajan, H. Humadi, and I. Zhitomirsky, "Cathodic electrodeposition of $\mathrm{MnOx}$ films for electrochemical supercapacitors," Electrochimica Acta, vol. 51, no. 15, pp. 3039-3045, 2006.

[18] J. K. Chang, C. H. Huang, W. T. Tsai, M. J. Deng, I. W. Sun, and P. Y. Chen, "Manganese films electrodeposited at different potentials and temperatures in ionic liquid and their application as electrode materials for supercapacitors," Electrochimica Acta, vol. 53, no. 13, pp. 4447-4453, 2008. 

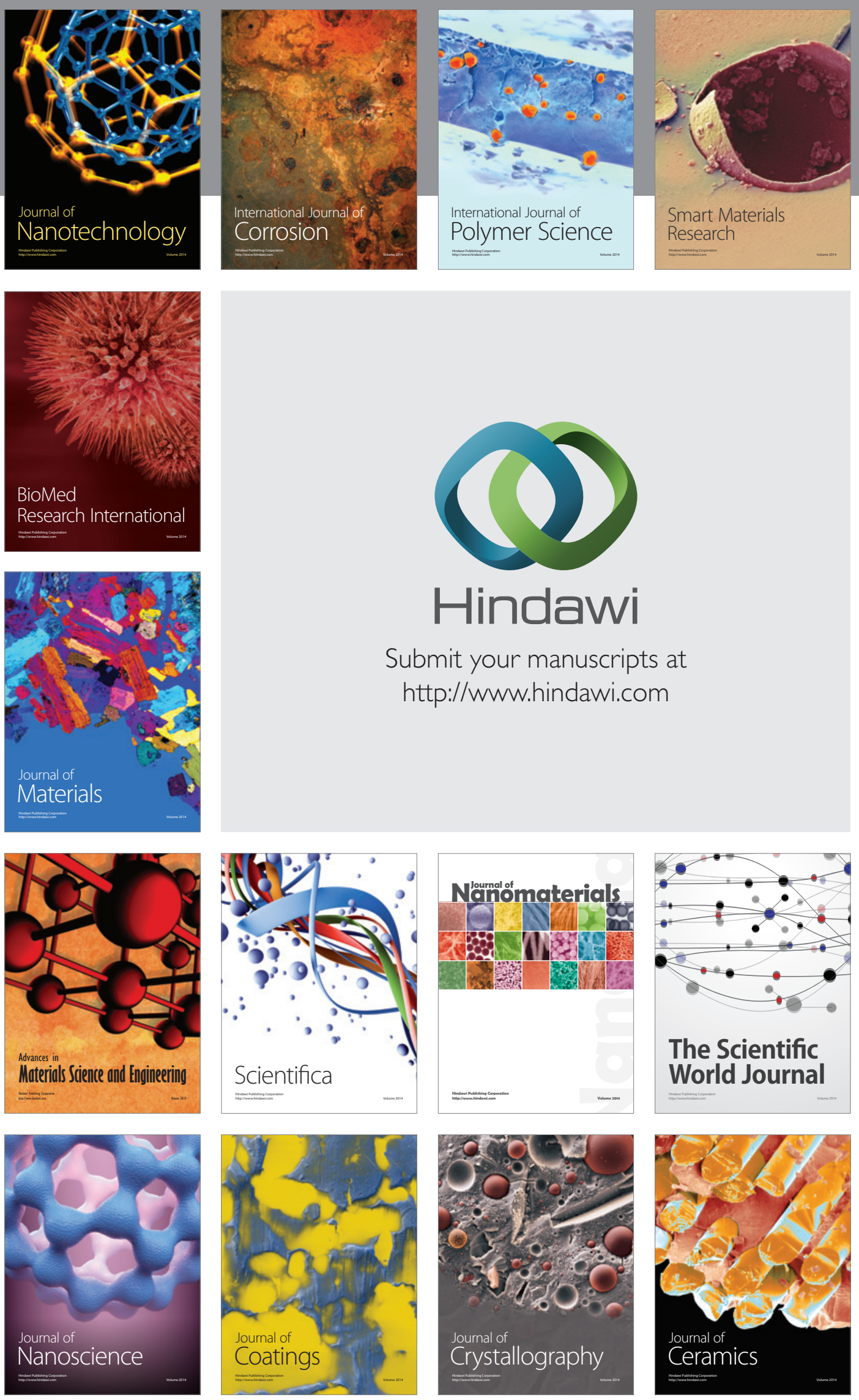

The Scientific World Journal

Submit your manuscripts at

http://www.hindawi.com

\section{World Journal}

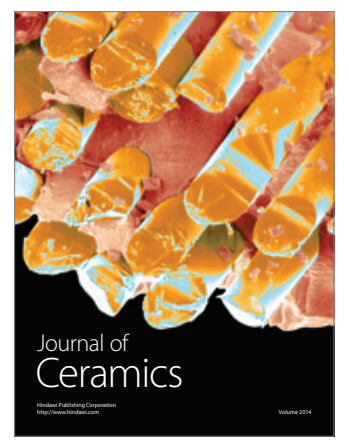

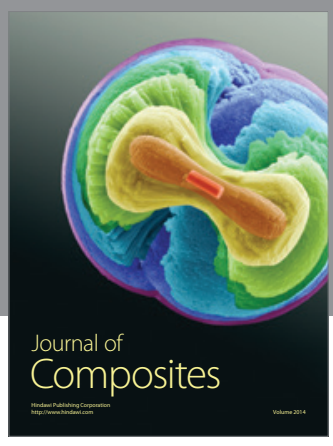
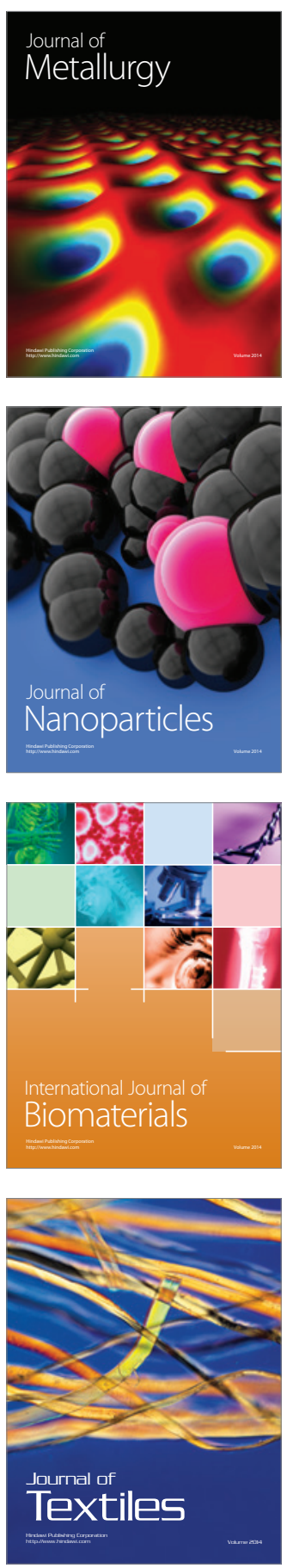